\title{
¡Hasta pronto maestras del siglo XX!! Una nueva vida os espera
}

La función del maestro ha cambiado radicalmente. Desde aquellos lejanos años en que inicié mi labor docente, donde la función principal del maestro consistía en administrar y regular todos los aspectos de la vida académica,

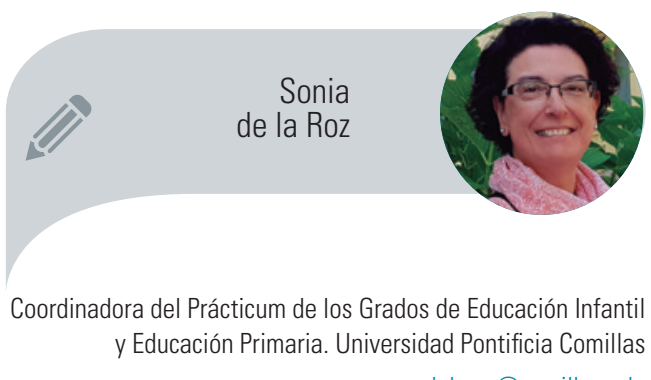

sdelaroz@comillas.edu hasta nuestros días, han aparecido numerosos desafíos, tanto profesionales como sociales, que las futuras maestras y maestros tendrán que afrontar. ¿Qué valores, qué perfil, qué rasgos personales han de tener aquellos estudiantes que se enfrentan a un contexto profesional tan complejo? Os invito a leer este texto que, en forma de cuento, trata de expresar lo esencial: para construir un gran maestro necesitamos partir de una gran persona. 


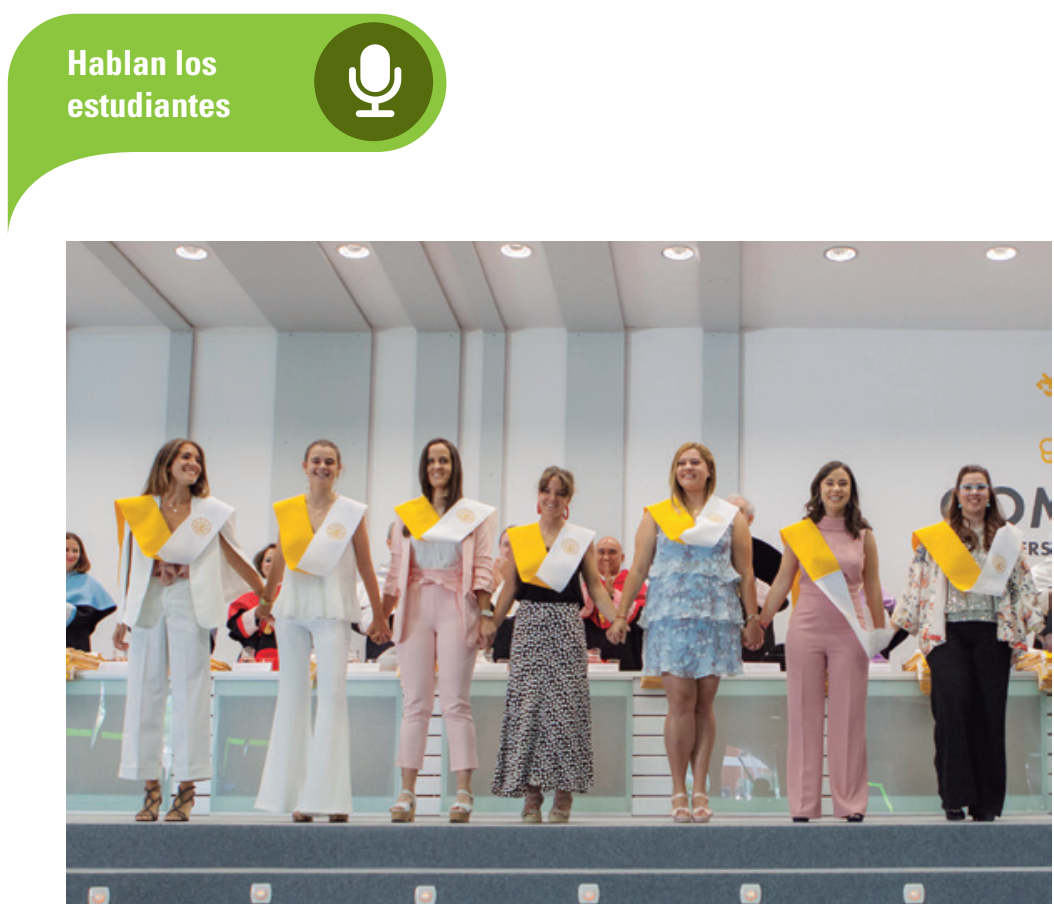

Cuando mis alumnos de $4 .^{\circ}$ curso de los dobles Grados de Educación Infantil y Educación Primaria me pidieron que escribiera un discurso para la ceremonia que, desde el ámbito de la tutoría, se había organizado para celebrar juntos el final de sus estudios de grado, me encontré en una encrucijada: ¿qué añadir a lo ya dicho a lo largo en cuatro años de diálogo y reflexión continuada, tras cuatro años de labor formativa colectiva y constante? Decidí, para inspirarme, volver la vista atrás, hacia mis primeros años como maestra de Educación Infantil y una idea surgió en mi mente: ¿qué escenarios tendrían que afrontar estas promociones de nuevos maestros? ¿Qué avatares personales y profesionales los esperaban en este contexto tan distinto al que yo viví al principio de mi carrera profesional?

La función del maestro ha cambiado radicalmente. Desde aquellos lejanos años en que inicié mi labor docente, donde la función principal del maestro consistía en impartir docencia y "regentar" el aula, es decir, administrar y regular todos los aspectos de la vida académica, hasta nuestros días, han aparecido numerosos desafíos, tanto profesionales como sociales, que estos alumnos tendrán que afrontar: la multiculturalidad, la irrupción de las ya imprescindibles tecnologías de la educación, la evolución del concepto de enseñanza-aprendizaje, con sus implicaciones metodológicas y didácticas, la transformación consiguiente de la organización escolar, con equipos docentes cada vez más complejos e interdependientes, la atención a la diversidad, en función de nuevos parámetros de igualdad y me- jora de las oportunidades educativas, los conceptos de transversalidad e integración curricular, la concepción ecológica del aprendizaje y del funcionamiento del aula, la visión competencial de los procesos..., todos los elementos de una nueva escuela, de una nueva educación e, inevitablemente, de la formación y del desempeño profesional de un nuevo maestro.

Los alumnos que egresan de nuestras aulas universitarias están abocados a ser maestros multifunción y multitarea: no es suficiente ya conocer los fundamentos de las disciplinas que conforman el currículo, sino que, además, han de adquirir sensibilidad hacia la diversidad cultural y las cuestiones de género, han de desarrollar la capacidad de coordinar y gestionar grupos de alumnos, de coordinar y participar en equipos docentes, de diseñar tareas y procesos, de comprender y desarrollar los fundamentos y técnicas de la evaluación, de organizar su aula como un ecosistema, de resolver y mediar en conflictos interpersonales, de implementar estrategias facilitadoras del aprendizaje, de manejar problemáticas extraacadémicas que influyen en el aula; han de ser, además, modelos de conducta, controladores de procesos, expertos en gestión académica y mucho más ${ }^{1}$.

Con todo esto en mente, la pregunta surgió inevitable: ¿qué valores, qué perfil, qué rasgos personales han de tener aquellos estudiantes que se enfrentan a un contexto profesional tan complejo? Y de ahí nació un texto que, en forma de cuento - tributo a las maravillosas clases de literatura compartidas con todos y cada uno de ellos - trataba de expresar lo esencial: para construir un gran maestro necesitamos tener una gran persona.

\section{Conclusión}

En la era de las tecnologías de la educación, de la diversidad de modelos

1 SaAvedra Rey, L. (2008). La profesión docente, sus múltiples funciones y campos de acción: aproximación a la resignificación pedagógica. Pedagogía y Saberes, 29, 65-72. DOI: https://doi. org/10.17227/01212494.29pys65.72 


\section{Una nueva vida}

Cuando se decretó el inicio de aquella nueva vida, la procesión de extraños personajes se puso en marcha.

Excepto el primero, que abría, solemne, el desfile, todos llevaban en sus manos unos cofres, que portaban como si fueran ofrendas. Cuando hubieron llegado a su destino, los depositaron sobre la arena y aguardaron el inicio de la ceremonia. No era su primera vez y tampoco sería la última. Sin prisa, todos se fueron situando en su lugar y se hizo el silencio. El ceremonioso personaje que abría la comitiva dio unos pasos al frente y, extendiendo su mano, dijo:

—Ahí está el mar, el mar inmenso, profundo, eterno, peligroso, inabarcable. Mi don es el mar —y dicho esto, volvió a su puesto.

Fue entonces cuando todos cayeron en la cuenta de que la pizpireta figura que iba justo detrás no estaba en su sitio. Nadie se extrañó por ello, ya estaban acostumbrados a los desatinos del personaje, que últimamente solía perderse por el final de la fila, discutiendo acaloradamente sobre vaya usted a saber qué con el orondo individuo que generalmente cerraba el cortejo. Al darse cuenta de que era su turno se adelantó a trompicones, salpicando a todos con la arena que levantaba con sus ridículos taconcitos. Sin resuello, abrió la caja que yacía en la arena y al punto salieron flotando, breves y delicadas como perlas, un racimo de burbujas de un color blanco azulado, que fueron elevándose en la brisa. El personaje cogió delicadamente una de ellas:

-Esta es la Audacia. Necesitarán mucha, mucha, para echarse a la espalda contratiempos y problemas. Y aquí está la Alegría. Que nunca los abandone y tiña siempre de blanco sus horas, sus sueños. Y este — dijo, por último— es el caprichoso e inconsistente Azar. Que les sea propicio y les ofrezca la mejor de las venturas en este viaje. Las burbujas nacaradas se dirigieron al mar girando blandamente en la brisa de la mañana.

— ¡Mi turno! — dijo con voz nasal el estrafalario personaje que iba a continuación. Y al decirlo golpeó a la de los tacones con sus inmensas narices, enormes, superlativas, como sacadas de un soneto. Al abrir su cajita surgieron en tropel verdes burbujas juguetonas que se alejaron empujándose unas a otras, revoloteando en el aire sutil de la playa. - Esta es la Energía, que falta les hará para seguir el ritmo, jornada tras jornada. Y esta — añadió - es la Esperanza, que les ayudará a entender que no importa el fracaso, ni la duda, ni la desilusión, ni la dificultad, que lo que importa es continuar persiguiendo sus sueños. Y aquí tengo un poquito de Experiencia, que con la ayuda del Esfuerzo... —el personaje atrapó una burbuja enorme e importuna que pugnaba por sentarse en sus narices - les allanará el camino, porque todo lo que vale, cuesta, y lo que vale mucho, cuesta mucho.

Una burbuja molesta, pesada y pringosa, como cubierta de manchas de tinta, se acercó peligrosamente a los presentes, amenazando con tiznarles la cara y deslucir aquel ritual tan largamente anhelado.

— ¡No, tú no! —levantó la voz, enfadado, el narigudo. Y empujó sin miramientos a la impertinente al fondo de la caja.

—Pero, ¿por qué no la dejas volar? ¿Por qué la condenas a quedarse encerrada? —-preguntó alguien.

—Para que en esta nueva vida — susurró el aludido— nunca vuelvan a decir "En plan".

Antes de que el narigón hubiera terminado, su curioso compañero, retorcido y tortuoso como una culebrilla, ya había dejado escapar un buen número de burbujas amarillas, que se desparramaron como un tropel de mariposas brillantes por la playa. A duras penas pudo atrapar tres 0 cuatro, mientras que las demás se alejaban, empujándose como niños que jugaran en el patio del recreo.

—Aquí traigo la Sabiduría. Deseo que les asista en sus decisiones, en sus trabajos; la Sabiduría es hermana de la Experiencia, recogida en el pasado, madurada en el presente y proyectada hacia el futuro. Que la Sabiduría y su pequeño aliado, el Sentido común, — dijo tratando de pillar a una pequeña traviesa que se escabullía entre sus dedos — les procuren claridad de pensamiento para discernir los qués, los cómos, los cuándos y los porqués de su existencia.

Casi no pudo terminar. El tipo larguirucho de anchos hombros que le seguía, carraspeó y aupándose cuán largo era, elevó al cielo un chorro de burbujas grises que parecían hechas de nube y de luz de luna.

—Yo les traigo el Tiempo — dijo con suavidad — para que puedan aprender día a día, para que sus esfuerzos fructifiquen y sus sueños se cumplan y para que, con ayuda del Tesón aprendan a no cejar nunca en su empeño. También traigo la Ternura para que sepan infundir ánimo y consuelo en los rostros de todos los que los miren. Y también una gotita de Templanza, para aceptar que las cosas no serán, muchas veces, como ellos esperan y, aun así, seguir repartiendo sonrisas.

Era el turno del tipo retorcido y jorobado que le seguía, y que, con un breve movimiento, dejó salir de su caja un enjambre de burbujas rojas que, como fresas aladas, se desparramaron por la playa.

- Yo les ofrezco la Risa. Que resuene siempre acompañada, nunca sola, a lo largo y ancho de sus vidas como la música de una banda sonora. Y también traigo la Reflexión y su íntima amiga la Razón — dijo alcanzando una burbuja que le rondaba como una pequeña avispa veraniega—. Necesitarán mucho de ambas para aprender, para comprender, para enseñar.

El silencio se hacía cada vez más consistente en la playa. Ya solo quedaba el voluminoso individuo que cerraba el grupo y que esperaba, pacientemente, su turno.

— Y yo — dijo liberando un ramillete de burbujas rosas y violetas que tiñeron de colores el espacio— les ofrezco Objetivos, que son como el horizonte que nos señala la ruta cuando no podemos ver bien el camino. Y les doy mi antídoto contra el Olvido. Que nunca se desprendan de lo que han aprendido y de lo que aún les queda por aprender. Que atesoren para siempre los rostros, los nombres, las miradas que han ido encontrando en su camino y las que vendrán: sonrisas desdentadas, bostezos, orejas de soplillo, gritos en el patio, rodilleras, cuentos, canciones. Que recuerden siempre los "profe, no me sale", los "profe, cuánto te quiero" y los "profe, ¿esto entra en el examen?". Que nunca olviden las risas y los Ilantos, que son los hilos de la trama de la vida. Una vida que se inicia aquí y que, ojalá, y este es mi presente, les haga tan felices como merecen.

Y flotaron las burbujas sobre aquel mar azul que ya esperaba a sus marineros. Llevaba cada una grabado un nombre y un don. Estaban todos y cada uno: la paciencia, el ingenio, la nobleza, la templanza, la bondad, la delicadeza, la inteligencia, la pasión. Flotaron sobre el mar y se alejaron.

Y, cumplido todo, la comitiva se fue. Ya estaba todo dicho, solo quedaba una última cosa que hacer. Era el momento de la despedida y de un nuevo comienzo. Nuevas vidas nacían, plenas de dones y proyectos, dispuestas a surcar el mar, hermoso, terrible, infinito.

El mar, sí. Ahí está el mar. Lo habéis ido conociendo poco a poco, os habéis adentrado apenas en su espuma, habéis aprendido a amarlo y a temerlo. Pero es vuestro, os lo habéis ganado, estimados alumnos, colegas, maestros, ahí está el mar, y ahora ¡A remar! ¡A remar! ¡A remar! 


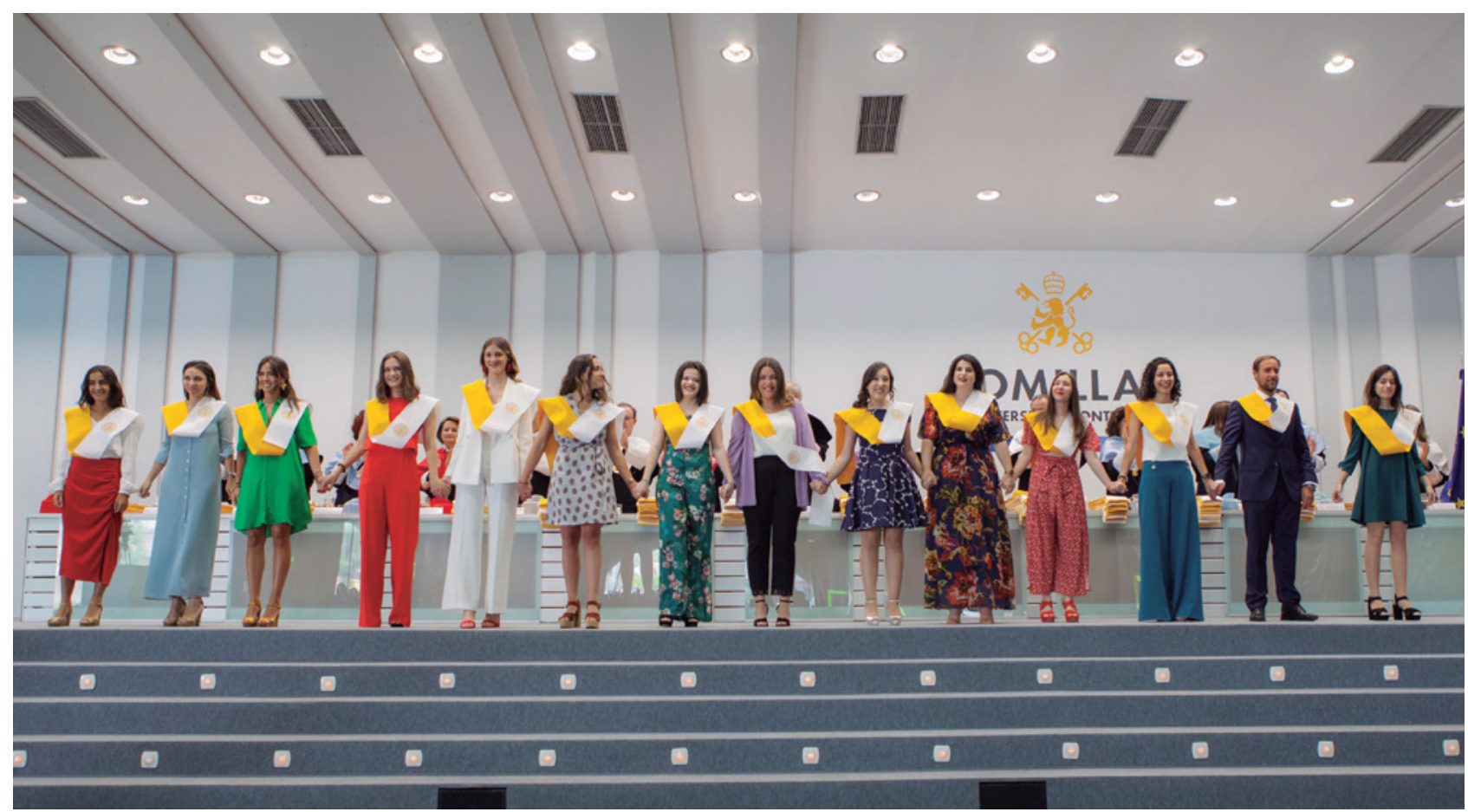

metodológicos, de la innovación como panacea para mejorar la calidad educativa, corremos el peligro de olvidar que, en definitiva, el funcionamiento de los alumnos, sus ganas de aprender, su compromiso con su proceso de desarroIlo intelectual, ético y social, dependen, en gran medida, del maestro: nada sustituye el viejo y a veces olvidado método del contacto persona-persona, del diálogo basado en el afecto y el respeto mutuo, del conocimiento -experiencia de vida - transmitido en el contacto bruneriano entre el docente y el alumno. Para mejorar la calidad de la enseñanza podemos y debemos implementar muchas

\section{El funcionamiento de los alumnos, sus ganas de aprender, su compromiso con su proceso de desarrollo intelectual, ético y social, dependen, en gran medida, del maestro}

e importantes medidas pedagógicas, políticas y económicas, pero la infalible, la que, seguro, redundará en la mejora del funcionamiento de las aulas, de la motivación de los alumnos, de sus deseos de aprender y de mejorar como personas, es la formación de buenos, sólidos y grandes maestros •

\section{(-) hemOS HABLADO DE \\ Formación de maestros; prácticum magisterio; educación en valores; didáctica de la lengua y la literatura.}

Este artículo fue solicitado por PADRES Y MAESTROS en marzo de 2019, revisado y aceptado en junio de 2019. 